\title{
Crystal Growth, Room Temperature Crystal Structure and Phase Transitions of $\mathrm{KMnPO}_{4}$
}

\author{
Marcos Luján*, Frank Kubel, Hans Schmid \\ Département de Chimie Minérale, Analytique et Appliquée, Faculté des Sciences, \\ Université de Genève 30, quai Ernest-Ansermet, CH-1211 Genève 4, Switzerland \\ Z. Naturforsch. 50b, 1210-1214 (1995); received February 20, 1995 \\ Manganese Potassium Orthophosphate, Crystal Structure, Crystal Growth, Phase Transitions \\ Single crystals of $\mathrm{KMnPO}_{4}$ grown in a $\mathrm{KCl}$ flux show ferroelastic domains. The structure \\ was determined on an optically controlled single domain crystal by X-ray diffraction methods. \\ The cell is triclinic with dimensions $a=5.4813(5), b=8.627(1), c=8.887(1)$, in $\AA$, $\alpha=$ \\ $87.73(1)^{\circ}, \beta=89.10(1)^{\circ}, \gamma=88.01(1)^{\circ}, V_{\mathrm{M}}=419.6(1) \AA^{3}$ and $Z=4$. The structure is closely \\ related to the stuffed $\beta$-tridymite type. DTA experiments between room temperature and \\ $1000{ }^{\circ} \mathrm{C}$ and polarized light microscopy observations showed four phase transitions: at 165 , \\ 330,353 and $707^{\circ} \mathrm{C}$.
}

\section{Introduction}

At present the structures of many $\mathrm{M}^{\prime} \mathrm{M}^{\prime \prime} \mathrm{PO}_{4}$ phosphates are known, where $\mathrm{M}^{\prime}$ stands for a monovalent cation and $\mathrm{M}^{\prime \prime}$ for a divalent cation. The structures found are closely related to three main structural types. The olivine type is adopted when the $\mathrm{M}^{\prime}$ and $\mathrm{M}^{\prime \prime}$ cations have a similar ionic radius of about $0.7 \AA$, for example $\mathrm{M}^{\prime}=\mathrm{Li}$ and $\mathrm{M}^{\prime \prime}=\mathrm{Fe}$, $\mathrm{Ni}, \mathrm{Co}, \mathrm{Mn}, \mathrm{Cd}$. In this case $\mathrm{M}^{\prime}$ and $\mathrm{M}^{\prime \prime}$ are found in octahedral environments, formed by the oxygen atoms of the $\mathrm{PO}_{4}$ tetrahedra $[1,2]$. When the $\mathrm{M}^{\prime}$ cation is larger than $\mathrm{M}^{\prime \prime}$, the beryllonite and stuffed $\beta$-tridymite type are often found. In this case $\mathrm{M}^{\prime}$ has a coordination number of six or higher, and $\mathrm{M}^{\prime \prime}$ becomes tetrahedrally coordinated. The $\mathrm{M}^{\prime \prime} \mathrm{O}_{4}$ and $\mathrm{PO}_{4}$ tetrahedra form sixmembered rings of alternating $\mathrm{M}^{\prime \prime} \mathrm{O}_{4}$ and $\mathrm{PO}_{4}$ groups. The rings form layers which are interconnected in a way that the rings form tunnels perpendicular to the layer plane to form a three-dimensional network with large cavities in which the $\mathrm{M}^{\prime}$ cations are located [3-5].

Despite the fact that the $\mathrm{PO}_{4}$ group forms a rather rigid tetrahedron, the network is quite flexible because rotations of the $\mathrm{PO}_{4}$ and $\mathrm{M}^{\prime \prime} \mathrm{O}_{4}$ tetrahedra produce only very small changes in bond angles and bond distances. As a consequence these types of structure undergo a series of phase transi-

* Reprint requests to M. Luján. tions as the temperature is changed. This confers interesting ferroelastic and ferroelectric properties to this family of compounds $[1,5-8]$. Therefore we have undertaken the study of the structure and properties of a series of $\mathrm{KM}^{\prime \prime} \mathrm{PO}_{4}$ phosphates. In this work we give a method for the synthesis of single crystals of $\mathrm{KMnPO}_{4}$ and details on the determination of their structure at room temperature. DTA experiments and observations by means of polarized light microscopy have also been carried out with a view to determine phase transitions in $\mathrm{KMnPO}_{4}$ upon heating.

\section{Crystal Growth of $\mathrm{KMnPO}_{4}$}

Single crystals of $\mathrm{KMnPO}_{4}$ were synthesized by reacting a mixture of $\mathrm{MnO}$ and $\mathrm{KPO}_{3}$ in a $\mathrm{KCl}$ flux. The mixture was placed in a platinum crucible and heated to $1030{ }^{\circ} \mathrm{C}$ followed by slow cooling. $\mathrm{KPO}_{3}$ can easily be prepared by heating $\mathrm{K}_{2} \mathrm{HPO}_{4}$ to $300{ }^{\circ} \mathrm{C}$ for a few hours [9]. This is a very versatile method which can be used for the preparation of a very wide series of anhydrous double orthophosphate salts. The only drawback is the evaporation of the flux which is very corrosive. Moreover, evaporation destabilises the crystal growth. This can be overcome by sealing the crucible.

Small pink-violet prism shaped needles were obtained, the larger ones had dimensions of about $0.3 \times 0.3 \times 2.0 \mathrm{~mm}$. Under optical examination by polarized light microscopy, a complicated pattern

0932-0776/95/0800-1210\$06.00 (c) 1995 Verlag der Zeitschrift für Naturforschung. All rights reserved. 
of ferroelastic domains is visible, indicating the presence of at least one ferroelastic phase transition during cooling. The larger crystals have a tunnel-like defect which runs parallel to the needle axis. This type of defect is also found in crystals of $\mathrm{KNiPO}_{4}$ and $\mathrm{KCoPO}_{4}$ prepared by the same method [10]. The crystals show a very important dichroism. Their colour changes from pink when the direction of the polarisation vector of the light is parallel to the needle axis to red-blue when the polarisation becomes perpendicular to the needle axis.

Large amounts of $\mathrm{KMnPO}_{4}$ powder can be synthesized is an easier way by slowly heating an equimolar mixture of $\mathrm{MnO}$ and $\mathrm{KH}_{2} \mathrm{PO}_{4}$ to $1000^{\circ} \mathrm{C}$ and keeping the mixture for about $20 \mathrm{~h}$ at this temperature.

\section{Experimental}

A mixture of $1.54 \mathrm{~g}(21.8 \mathrm{mmol})$ of $\mathrm{MnO}, 2.57 \mathrm{~g}$ $(21.8 \mathrm{mmol})$ of $\mathrm{KPO}_{3}$ and $6.49 \mathrm{~g}(87.1 \mathrm{mmol})$ of $\mathrm{KCl}$ was placed in a $10 \mathrm{~cm}^{3}$ platinum crucible which was sealed by welding. The mixture was heated up to $1030^{\circ} \mathrm{C}$, soaked at this temperature for $4 \mathrm{~h}$ and slowly cooled $\left(2{ }^{\circ} \mathrm{C} / \mathrm{h}\right)$ down to $750{ }^{\circ} \mathrm{C}$. Then the system was left to cool down to room temperature. The small pink-violet needles were separated mechanically from the flux. The flux can also be washed out with hot water, but there is some decomposition of the $\mathrm{KMnPO}_{4}$ crystals, probably due to hydration.

\section{Phase Transitions in $\mathrm{KMnPO}_{4}$}

Two samples of $\mathrm{KMnPO}_{4}$ (140 and $160 \mathrm{mg}$ ) were studied by $D$ ifferential Thermal $A$ nalysis between room temperature and $1000^{\circ} \mathrm{C}$. Upon heating a first phase transition is seen at $165 \pm 3{ }^{\circ} \mathrm{C}$ manifesting itself as a change of the level of the base line. Peaks are found at 330 and $353{ }^{\circ} \mathrm{C}$ indicating two phase transitions. A last small peak is seen at $707^{\circ} \mathrm{C}$; above this temperature the base line has a very large drift. This may indicate an important change in the heat capacity of $\mathrm{KMnPO}_{4}$ above this temperature which may be connected with the phase transition. Upon cooling the phase transitions occur at $730,367,326$ and $100{ }^{\circ} \mathrm{C}$, respectively.

Single crystals were also studied. By heating them under simultaneous observation by means of polarised light microscope, the transition observed at $165^{\circ} \mathrm{C}$ in the DTA experiments has been confirmed: at about $165^{\circ} \mathrm{C}$, the ferroelastic domains begin to disappear and they are no longer visible at $175^{\circ} \mathrm{C}$. Upon cooling the ferroelastic domains appear around $97^{\circ} \mathrm{C}$. The pattern of ferroelastic domains is rather complicated, the ferroelastic domain walls present indicate a triclinic symmetry for the room temperature phase of $\mathrm{KMnPO}_{4}$, as was later determined by X-ray diffraction. We were not able to see optically the transitions at higher temperature, maybe because of an unfavourable cut orientation or because the transitions are not of ferroelastic nature.

\section{Structure of the room temperature phase of $\mathrm{KMnPO}_{4}$}

\section{Experimental}

Fortunately we were able to find a small crystal which appeared to be a ferroelastic single domain. Its dimensions were: $233 \times 24 \times 24 \mu \mathrm{m}$. A CAD- 4 Enraf-Nonius diffractometer with $\mathrm{CuK} \bar{\alpha}$ radiation $(\lambda=1.5418 \AA$ ) was used for measuring the reflections. The cell found was triclinic as determined from 25 reflections with $10^{\circ}<2 \theta<35^{\circ}$. After refinement by diffractometer techniques and least squares methods the cell parameters are: $a=$ 5.4813(5), $b=8.627(1), c=8.887(2)$ in $\AA$ and $\alpha=$ 87.73(1) $)^{\circ}, \beta=89.10(1)^{\circ}, \gamma=88.01(1)^{\circ}, V_{\mathrm{M}}=$ 419.6(1) $\left[\mathrm{A}^{3}\right], Z=4$. The crystals are elongated along the $[100]$ direction.

The intensities of 6028 reflections were measured $\left(\omega-2 \theta\right.$ scans, $\left.2 \theta_{\max }=67.9^{\circ}\right)$. From 1533 independent reflections, 1482 with $\mathrm{I}>2 \sigma$ were used for the structure determination and refinement. Two standard reflections measured every $120 \mathrm{~min}$. showed a maximum variation of $2.4 \%$ in the intensity. Absorption corrections were made by analytical integration considering the shape of the crystal $\left(\mu=37.27 \mathrm{~mm}^{-1}\right)$. All calculations were made with the program Xtal 3.2 [11]. The crystallographic data are summarized in Table I.

\section{Structure determination and description}

Analysis of the intensity statistics indicated a centrosymmetric space group, therefore $\mathrm{P} \overline{1}$ was taken as space group. Direct methods allowed the determination of the position of $\mathrm{Mn}, \mathrm{K}$ and $\mathrm{P}$ atoms. Subsequent series of difference Fourier synthesis yielded the oxygen positions. A full matrix refinement on $\left|F^{2}\right|$, first made with isotropic and then with anisotropic atomic displacement parameters, converged to a final $R=0.029\left(R_{w}=\right.$ 


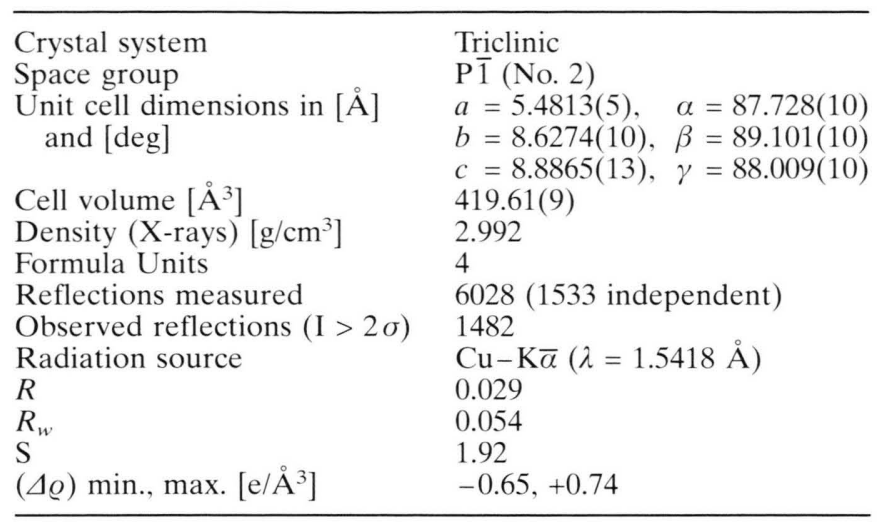

Table I. Crystallographic data for $\mathrm{KMnPO}_{4}$ at room temperature.
0.054). Extinction was refined using a Zachariasen model and dispersion was applied. The final atomic positions and isotropic thermal parameters are given in Table II*.

The structure is closely related to the $\beta$-tridymite type. Two projections of the structure, along the $b$ and $c$ axis, are given in Fig. 1. In this figure the $\mathrm{MnO}_{4}$ and $\mathrm{PO}_{4}$ groups are represented by tetrahedra, the larger tetrahedra corresponding to $\mathrm{MnO}_{4}$ and the smaller ones to $\mathrm{PO}_{4}$. Basically the structure consists of a network of six membered rings of alternating $\mathrm{MnO}_{4}$ and $\mathrm{PO}_{4}$ tetrahedra. The rings form layers perpendicular to the

Table II. Atomic positional and isotropic displacement parameters in $\left[\AA^{2}\right]$ for the room temperature phase of $\mathrm{KMnPO}_{4}$ (e.s.d.'s are given in parenthesis).

\begin{tabular}{llrll}
\hline Atom & $x / a$ & \multicolumn{1}{l}{$y / b$} & \multicolumn{1}{l}{$z / c$} & \multicolumn{1}{l}{$\mathrm{U}_{\text {iso }}$} \\
\hline $\mathrm{Mn}(1)$ & $0.6912(1)$ & $0.34279(8)$ & $0.41973(8)$ & $0.0163(2)$ \\
$\mathrm{Mn}(2)$ & $0.7270(1)$ & $-0.17634(8)$ & $0.10544(7)$ & $0.0153(2)$ \\
$\mathrm{K}(1)$ & $0.7606(2)$ & $-0.0018(1)$ & $0.6827(1)$ & $0.0238(3)$ \\
$\mathrm{K}(2)$ & $0.7821(2)$ & $-0.5049(1)$ & $0.8264(1)$ & $0.0251(3)$ \\
$\mathrm{P}(1)$ & $0.7672(2)$ & $0.2024(1)$ & $0.0924(1)$ & $0.0127(3)$ \\
$\mathrm{P}(2)$ & $0.7823(2)$ & $-0.2963(1)$ & $0.4444(1)$ & $0.0131(3)$ \\
$\mathrm{O}(1)$ & $0.6317(6)$ & $0.2041(4)$ & $0.9419(3)$ & $0.022(1)$ \\
$\mathrm{O}(2)$ & $0.2649(6)$ & $0.4533(3)$ & $0.4712(3)$ & $0.019(1)$ \\
$\mathrm{O}(3)$ & $0.6546(6)$ & $0.3262(4)$ & $0.1927(3)$ & $0.026(1)$ \\
$\mathrm{O}(4)$ & $0.4495(6)$ & $0.1948(3)$ & $0.5347(3)$ & $0.020(1)$ \\
$\mathrm{O}(5)$ & $0.0006(6)$ & $0.2195(3)$ & $0.4878(4)$ & $0.026(1)$ \\
$\mathrm{O}(6)$ & $0.1702(7)$ & $0.3243(4)$ & $0.7227(3)$ & $0.030(1)$ \\
$\mathrm{O}(7)$ & $0.0367(6)$ & $0.2411(4)$ & $0.0608(3)$ & $0.025(1)$ \\
$\mathrm{O}(8)$ & $0.7548(7)$ & $0.0430(4)$ & $0.1723(4)$ & $0.029(1)$ \\
\hline
\end{tabular}

* Further crystal and refinement details may be obtained from the Fachinformationszentrum Karlsruhe, D-76344 Eggenstein-Leopoldshafen (Germany) on quoting the depository number CSD 58818, the names of the authors and the literature quotation. $b$ axis. The stacking of the layers creates large tunnels, which run parallel to the [010] direction. The $\mathrm{K}$ ions are located in these tunnels. In the rings three adjacent tetrahedra are pointing up (U) rela-

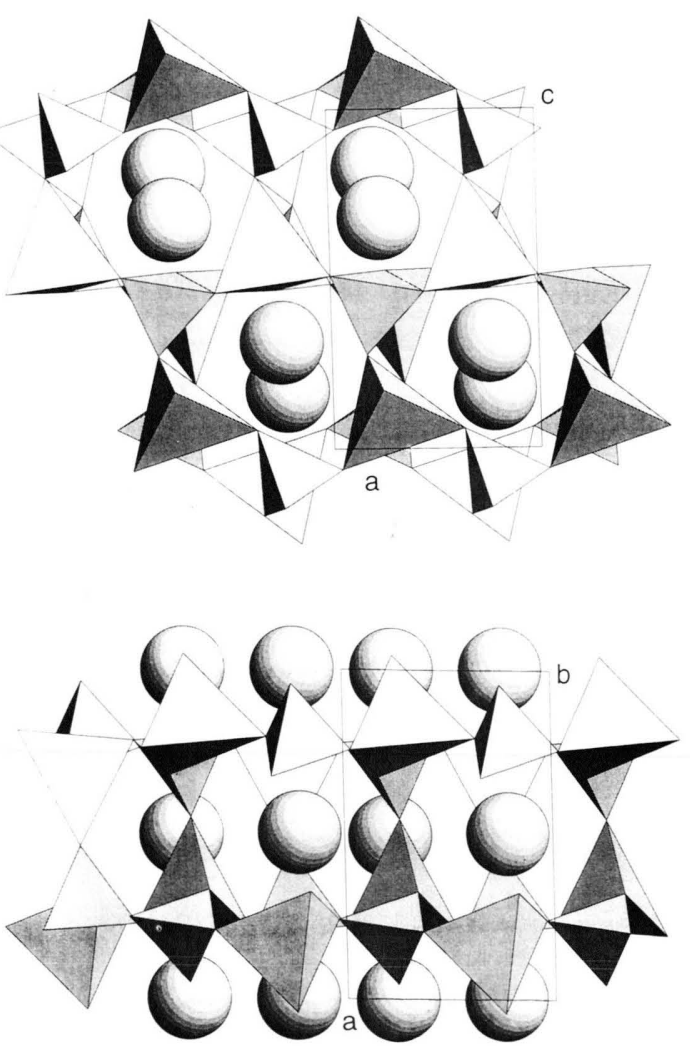

Fig. 1. Room temperature structure of $\mathrm{KMnPO}_{4}$. Two projections are drawn, one along the $b$-axis (top) and the other one along the $c$-axis (bottom). The large tetrahedra represent the $\mathrm{MnO}_{4}$ groups and the small ones the $\mathrm{PO}_{4}$ groups. The spheres represent the $\mathrm{K}$ ions. Drawing produced with the program ATOMS, by Shape Software. 


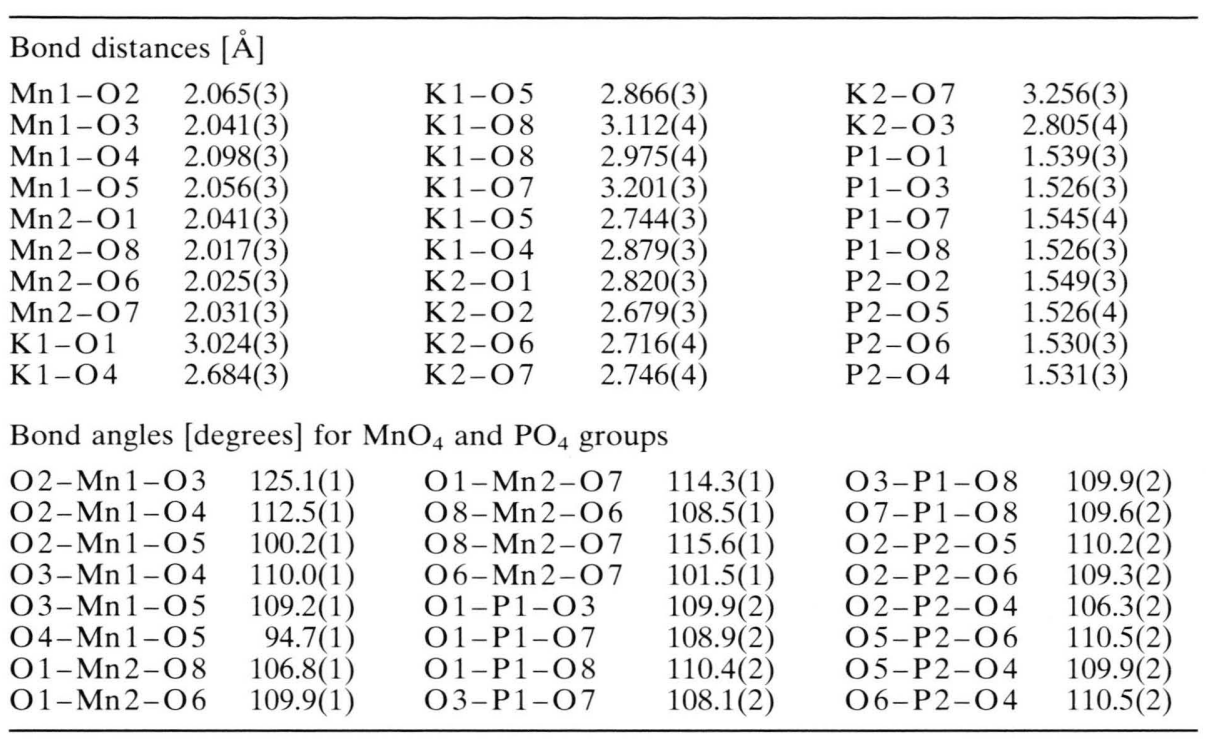

tive to the ring plane $\left(a^{\wedge} c\right)$ and the other three are pointing down (D) (UUUDDD rings). The orientation of the tetrahedra relative to the ring plane represents the main difference with respect to the structure of $\beta$-tridymite where the orientation of the $\mathrm{SiO}_{4}$ tetrahedra in the rings is UDUDUD.

There are two types of $\mathrm{PO}_{4}$ and $\mathrm{MnO}_{4}$ tetrahedra. The $\mathrm{PO}_{4}$ tetrahedra are quite regular, with $\mathrm{P}-\mathrm{O}$ distances in the range 1.526-1.549 $\AA$ and the $\mathrm{O}-\mathrm{P}-\mathrm{O}$ angles very close to $109.5^{\circ}$. This is consistent with the data of other phosphates and shows that the $\mathrm{PO}_{4}$ group forms quite a rigid tetrahedron. The $\mathrm{Mn}(1) \mathrm{O}_{4}$ and $\mathrm{Mn}(2) \mathrm{O}_{4}$ groups form relatively different tetrahedra, the $\mathrm{Mn}(1)-\mathrm{O}$ distances being slightly longer than the $\mathrm{Mn}(2)-\mathrm{O}$ distances. The $\mathrm{Mn}(1) \mathrm{O}_{4}$ tetrahedron is also much more distorted than $\mathrm{Mn}(2) \mathrm{O}_{4} \cdot \mathrm{K}(1)$ is surrounded by eight oxygen atoms at distances in the range 2.684-3.201 A, whereas $\mathrm{K}(2)$ has only six oxygen neighbours at $2.716-3.256 \AA$. A list of bond distances and angles is given in Table III.

\section{Discussion and Conclusions}

There are few examples of structures of double orthophosphate salts having a triclinic structure, the only other example known being $\mathrm{AgCoPO}_{4}$ [12], but it is not isotypic with $\mathrm{KMnPO}_{4}$. To the best of our knowledge the structure of $\mathrm{KMnPO}_{4}$ at room temperature represents a new structural type.

The four phase transitions detected between room temperature and $1000{ }^{\circ} \mathrm{C}$ show that this net-
Table III. Bond distances and bond angles in the room temperature phase of $\mathrm{KMnPO}_{4}$ (e.s.d.'s are given in parenthesis) work of six-membered rings of $\mathrm{PO}_{4}$ and $\mathrm{MnO}_{4}$ tetrahedra is quite flexible. The presence of a large $\mathrm{K}$ cation $\left(\mathrm{r}_{\mathrm{I}}=1.52 \AA[13]\right)$ seems to be essential for the formation of this type of network because the six membered rings allow the formation of large cavities in which the $\mathrm{K}$ ions are located. In the structures of $\mathrm{LiMnPO}_{4}$ [14] and $\mathrm{NaMnPO}_{4}$ [15] the Mn cations are found in octahedral environments. This leaves less space for the $\mathrm{Li}$ and $\mathrm{Na}$ ions, but as these are relatively small $\left(\mathrm{r}_{\mathrm{I}}=0.90\right.$ and $\mathrm{r}_{\mathrm{I}}=1.16$, respectively) the structure is still stable. It would be interesting to see if these two compounds have structural phase transitions at high temperature and what the structural changes are like. Upon heating, the thermal agitation has the effect of increasing the size of the ions and this could induce a phase transition where $\mathrm{Mn}$ is tetrahedrally coordinated and forming the same type of rings as in $\mathrm{KMnPO}_{4}$. This could happen in particular with $\mathrm{NaMnPO}_{4}$. The network described above is also found in other double salts containing a tetrahedral anion like sulphates and arsenates and a large cation (e.g. $\mathrm{CsLiSO}_{4}, \mathrm{RbLiSO}_{4}$, $\mathrm{KLiSO}_{4}, \mathrm{TlZnPO}_{4}$ [4, 16-17]). Many of these compounds also have one or several phase transitions, as well as modulated phases.

The structure of the prototype phase is known for some compounds of this type. It is interesting to see that most of them adopt an orthorhombic structure at high temperature, belonging to the 


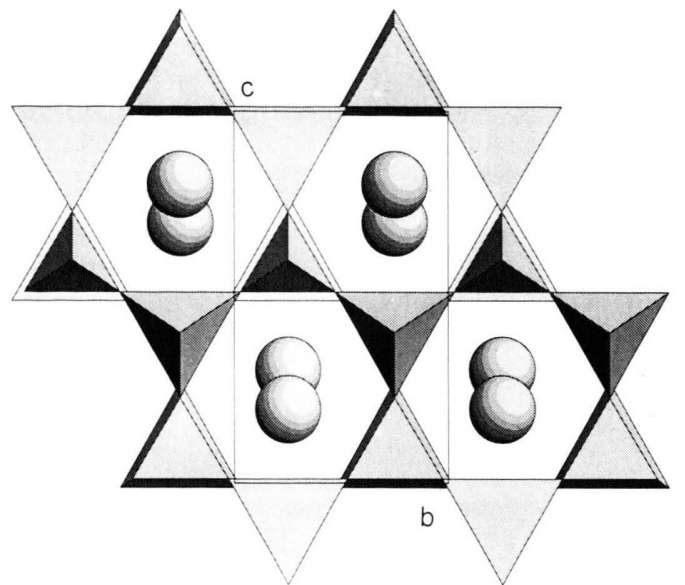

Fig. 2. Prototype phase of $\mathrm{CsZnPO}_{4}$ (above $310^{\circ} \mathrm{C}$ ) according to Ref. 5. Projection along the $a$-axis that shows the six membered rings of $\mathrm{PO}_{4}$ and $\mathrm{ZnO}_{4}$ tetrahedra. These tetrahedra lie in a mirror plane perpendicular to the $b$-axis. Drawing produced with the program ATOMS, by Shape Software.

centrosymmetric space group Pnma. This is for example the case for $\mathrm{CsZnPO}_{4}[6]$ and $\mathrm{CsLiSO}_{4}[16]$. A drawing of the structure of $\mathrm{CsZnPO}_{4}$ above $310{ }^{\circ} \mathrm{C}$ is given in Fig. 2, the six-membered rings being easily distinguished. In this phase the $\mathrm{PO}_{4}$ and $\mathrm{ZnO}_{4}$ tetrahedra are located in a mirror plane perpendicular to the orthorhombic $b$-axis and the orientation of the tetrahedra relative to the $b^{\wedge} c$ plane is UUUDDD. This relative orientation does not change on cooling through the phase transitions. The $\mathrm{PO}_{4}$ and $\mathrm{M}^{\prime \prime} \mathrm{O}_{4}$ tetrahedra deviate from their positions in the prototype phase, either by small rotations around the axis perpendicular to the ring plane or by tilting away from this axis. These two kinds of movements do not imply large changes in bond distances and bond angles and do not allow a change in the orientation of the tetrahedra relative to the ring plane. This may be the reason why this type of three-dimensional network is so flexible and allows such a variety of phase transitions which confers ferroelectric and ferroelastic properties to these crystals. This flexibility may also account for the presence of modulated phases as in $\mathrm{KCoPO}_{4}$ [18]. In the case of $\mathrm{KMnPO}_{4}$ we can expect that the relative orientation of the tetrahedra in the ring does not change throughout all the phase transitions. Therefore the prototype phase may be isotypic with that of $\mathrm{CsZnPO}_{4}$. The sequence of point groups in the sense of decreasing symmetry upon cooling could be the following: $\mathrm{mmm} \rightarrow(\mathrm{mm} 2) \rightarrow 2 / \mathrm{m} \rightarrow 1$.

The high temperature phases of $\mathrm{KMnPO}_{4}$ are under study and also the magnetic properties. Since $\mathrm{Mn}^{2+}$ is a paramagnetic ion, a magnetic phase transition is possible at low temperature towards a magnetically ordered state. The most probable "super exchange" interaction path will operate via two oxygen atoms $\left(\mathrm{Mn}-\mathrm{O}-\mathrm{O}-\mathrm{Mn}^{\prime}\right)$.

\section{Acknowledgements}

Thanks are due to $\mathrm{H}$. Lartigue for the DTA measurements and to the Swiss National Science Foundation for support.
[1] B. Elouadi, L. Elammari, Ferroelectrics 107, 253 (1990).

[2] B. Elouadi, L. Elammari, J. Ravez, Ferroelectrics 56, 17 (1984).

[3] M. Luján, F. Kubel, H. Schmid, Z. Naturforsch. 49b, 1256 (1993).

[4] M. Andratschke, K.-J. Range, C. Weigl, U. Schießl, F. Rau, Z. Naturforsch. 49b, 1282 (1993).

[5] D. Blum, A. Durif, M. Averbuch-Pouchot, Ferroelectrics 69, 283 (1986).

[6] D. Blum, J. C. Peuzin, J. Y. Henry, Ferroelectrics 61, 265 (1984).

[7] P. Fischer, M. Luján, F. Kubel, H. Schmid, Ferroelectrics 161, 385 (1994).

[8] L. Elammari, B. Elouadi, G. Müller-Vogt, Phase Transitions 13, 29 (1988).

[9] J. Khiel, G. H. Wallace, J. Amer. Chem. Soc. 49, 376 (1927).
[10] M. Luján, J.-P. Rivera, S. Kizhaev, H. Schmid, O. Triscone, J. Muller, Z.-G. Ye, B. Mettout, R. Bouzerar, Ferroelectrics 161, 77 (1994).

[11] S. D. Hall, H. D. Flack, J. M. Stewart Editors of Xtal 3.2: User's Manual.

[12] I. Tordjman, J. C. Gentel, A. Durif, M. T. Averbuch, R. Masse, Materials Research Bulletin 13, 29 (1978).

[13] R. D. Shannon, Acta Cryst. A 32, 751 (1976).

[14] S. Geller, J. L. Durand, Acta Cryst. 13, 325 (1960).

[15] J. Moring, E. Kostiner, J. Solid State Chem. 61, 379 (1986).

[16] T. Asahi, K. J. Hasebe, J. Phys. Soc. Jpn. 57, 4184 (1988).

[17] T. R. Welberry, A. M. Glazer, J. Appl. Cryst. 27, 733 (1994).

[18] M. Luján, H. Schmid, Ferroelectrics, to be published. 